\title{
Management of Galassi type 3 Arachnoid cyst- A Case Report \\ -Birat ThapaMagar,MBBS ${ }^{1}$, Dinesh K. $\quad$ Thapa,MBBS $^{1}$ Karuna Tamrakar(Karki),MS, MCh ${ }^{1}$, Pankaj Raj Nepal, FCPS ${ }^{1}$ \\ ${ }^{1}$ Department of Neurosurgery, B \& C Medical College Teaching Hosptial, Birtamode, Jhapa.
}

Arachnoid cyst is a benign congenital lesion which can be located in various regions like; suprasellar, sylvian, posterior fossa, spine \& so on. The most common location of arachnoid cyst is the middle fossa or sylvian fissure usually behind the greater wing of sphenoid bone $(50 \%)$ ).Here we are presenting a case of a 59 year-old woman brought to the emergency department with history of sudden onset loss of consciousness associated with generalized tonic clonic seizure. CT-scanning of head showed Galassi type 3 arachnoid cyst. She was managed with fenestration and partial marsupialization of cyst with excellent outcome.

Keywords: Arachnoid cyst, marsupialization of cyst, fenestration of arachnoid cyst. seizure

\begin{abstract}
$\mathrm{A}$
59 year-old woman brought to the

emergency department with history of sudden onset loss of consciousness associated with generalized tonic clonic seizure few hours before presentation. On arrival she was eye opening to pain, incomprehensible sounds and flexon motor response with pupils $3 \mathrm{~mm}$ bilaterally reactive to light and plantar right sided up going. Her vitals were stable.

After initial assessment \& resuscitation, Phenytoin was loaded and CT-scanning of head was done, which showed - large CSF intensity lesion in left sylvian region with features of marked midline shift suggestive of Galassi type 3 arachnoid cyst.
\end{abstract}

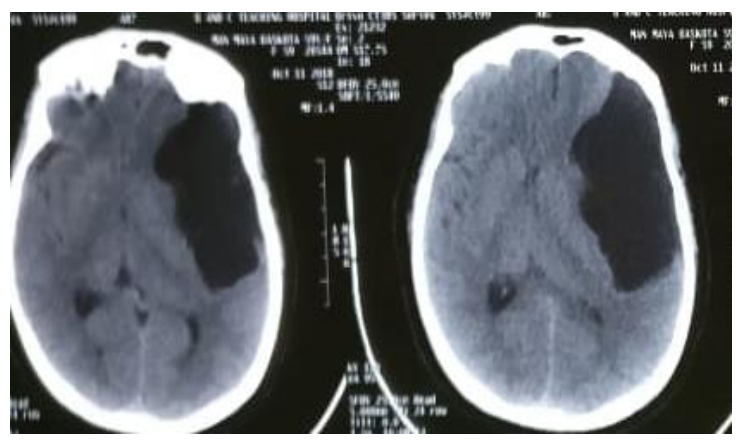

Figure 1: CT head on presentation showing Galassi type 3 arachnoid cyst with severe mass effect.

Baseline investigations were done \& patient was prepared for operation after taking informed consent from the patient's party.

Right pterional craniotomy was done with osteoplastic bone flap. Dura was opened in curvilinear fashion based inferiorly.

A large cyst was identified filled with clear fluid and vessels were all running in the cyst wall. Cyst was seems to compress the 
frontal and the temporal lobe and the sylvian fissure was wide open exposing the internal carotid artery and the middle cerebral artery. The insular and the opercular segments of the middle cerebral artery was clearly seen in the basal part of the cyst wall and was separated with the perioptic cistern with a thin layer of intact arachnoid membrane. The brain pulsation was minimum before opening the cyst wall.

The cyst cavity was approached by opening the superficial layer of the arachnoid membrane and then fenestrations were made with the preoptic, opticocarotid and caroticotentorial cisterns. A good brain pulsation was noticed and procedure was completed with partial marsupialization of cyst wall.

Closure was done with primary dural closure, repositioning bone flap and skin closed in layers with a multihole suction drain in subgaleal space.

Patient was gradually weaned off from ventilator and extubated in ICU.

Postoperative course was uneventful. Patient started mobilization from third day with no focal neurological deficit. She got discharged after cranial sutures were removed.

MRI brain was done on the follow up of 3 month which showed centralized midline with no further compression on the lobes around the cyst. The volume of the cyst was reduced and remaining cavity might be secondary to underdeveloped lobes.

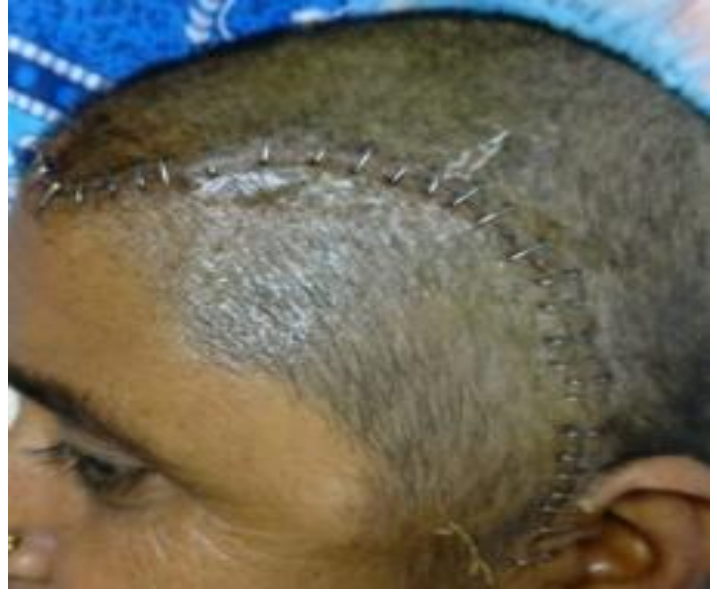

Figure 2: Surgical scar of the pterional craniotomy.

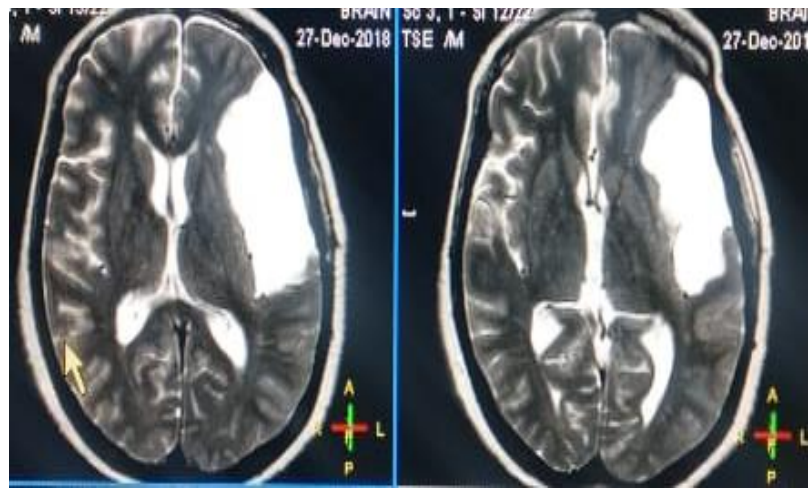

Figure 3: Follow-up T2 weighted MRI at three months showing centralized midline and compressive effect in the brain lobes.

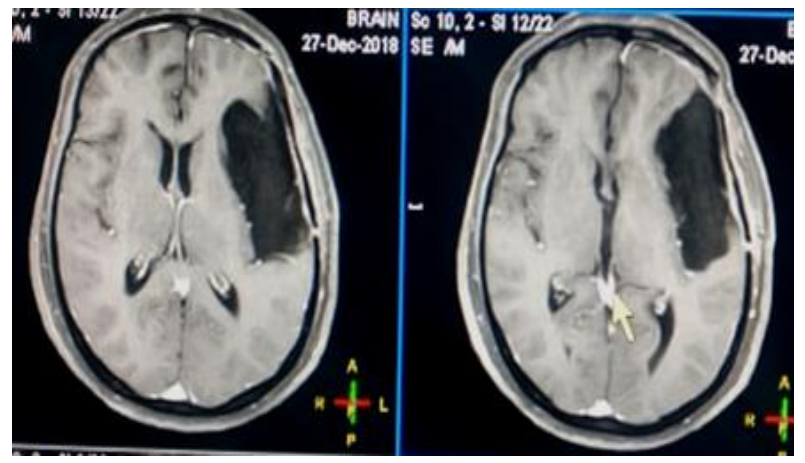

Figure 4: Follow-up contrast enhanced MRI showing no abnormal enhancement. 


\section{Discussion:}

Arachnoid cyst is a benign congenital lesion which can be located in various regions like; suprasellar, sylvian, posterior fossa, spine \& so on. The most common location of arachnoid cyst is the middle fossa or sylvian fissure usually behind the greater wing of sphenoid bone $(50 \%))^{1}$

Presentation of arachnoid cyst can vary from SDH or bleed into cyst mass effect or seizure. ${ }^{1}$ Galassi et.al has described the classification system of arachnoid cyst based upon its size, shape \& communication with the cistern. ${ }^{2,3}$ Type I sylvian arachnoid cyst has biconvex appearance which is freely communicated with cistern $\&$ are best managed conservatively. Type II sylvian arachnoid cyst are rhomboid shaped \& partially communicated with cistern. These are also managed conservatively until there is acute growth, bleed or other problems. Type III sylvian arachnoid cyst are huge in size with mass effect \& no communication with cistern, hence surgical treatment are advised to deal this type of arachnoid cyst. $^{2,3}$

\section{References:}

1. Piatt Jr JH. Unexpected findings on brain and spine imaging in children. Pediatr Clin North Am. 2004;51:507-527.

2. Peraud A, Ryan G, Drake JM. Rapid formation of a multicompartment neonatal arachnoid cyst. Pediatr Neurosurg. 2003;39:139-143

3. Galassi E, Tognetti F, Gaist G, et al. CT scan and metrizamide CT cisternography in arachnoid cysts of the middle cranial fossa: classification and pathophysiologic aspects. Surg Neurol. 1982;17:363-369.

4. Cincu R, Agrawal A, Eiras J. Intracranial arachnoid cysts: Current concepts and treatment alternatives. Clin Neurol Neurosurg. 2007;109:837-843.
Various surgical treatments are available $\&$ all of them have showed relatively similar outcome in terms of its recurrence \& morbidity. Cystoperitoneal shunt, marsupilization of cyst, fenestration of cyst with the nearby cistern either endoscopically or microsurgically, arachnoidoplasty, are the various surgical options available. ${ }^{4,5,6}$

In this case, this lady presented with the features of raised ICP \& seizure which was dealt surgically with microsurgical marsupilization \& fenestration of cyst with perioptic cisterns. The overall outcome was good which can be appreciated in follow up MRI scan.

\section{Take Home Message:}

Though arachnoid cyst is congenital lesion, it can present any time in life with different sorts of problem \& appropriate management can definitely help to alleviate those symptoms. 
5. Spacca B, Kandasamy J, Mallucci CL, Genitori L. Endoscopic treatment of middle fossa arachnoid cysts: a series of 40 patients treated endoscopically in two centres. Childs Nerv Syst. 2010;26:163-172.

6. Shim K-W, Lee Y-H, Park E-K, et al. Treatment option for arachnoid cysts. Childs Nerv Syst. 2009;25:1459-1466. 